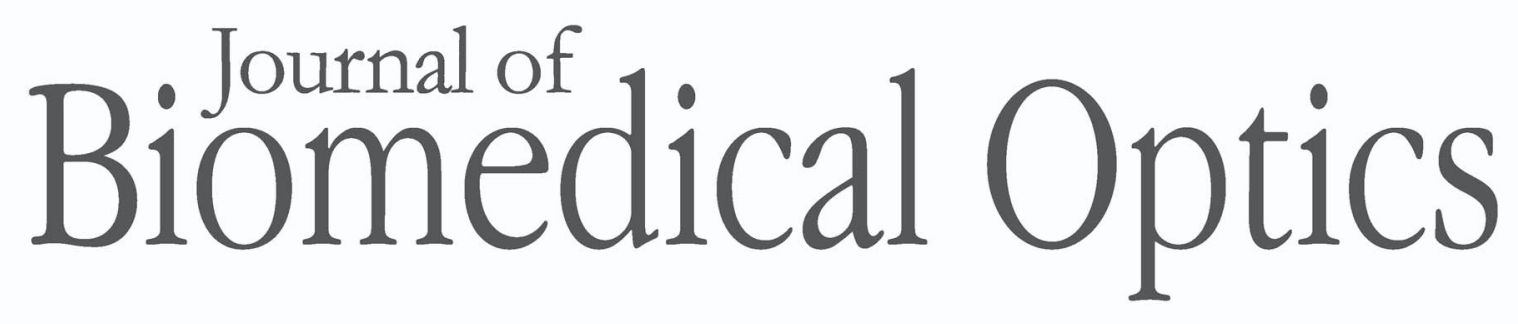

\title{
Simulation of the temperature increase in human cadaver retina during direct illumination by $150-\mathrm{kHz}$ femtosecond laser pulses
}

Hui Sun

Nora Hosszufalusi

Eric R. Mikula

Tibor Juhasz 


\title{
Simulation of the temperature increase in human cadaver retina during direct illumination by $150-\mathrm{kHz}$ femtosecond laser pulses
}

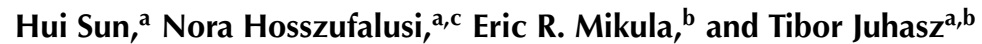 \\ a University of California, Irvine, Department of Ophthalmology, Irvine, California 92697 \\ b University of California, Irvine, Department of Biomedical Engineering, Irvine, California 92697 \\ 'Semmelweis University, 3rd Department of Internal Medicine, Budapest
}

\begin{abstract}
We have developed a two-dimensional computer model to predict the temperature increase of the retina during femtosecond corneal laser flap cutting. Simulating a typical clinical setting for $150-\mathrm{kHz}$ iFS advanced femtosecond laser (0.8- to 1- $\mu$ J laser pulse energy and 15-s procedure time at a laser wavelength of $1053 \mathrm{~nm})$, the temperature increase is $0.2^{\circ} \mathrm{C}$. Calculated temperature profiles show good agreement with data obtained from ex vivo experiments using human cadaver retina. Simulation results obtained for different commercial femtosecond lasers indicate that during the laser in situ keratomileusis procedure the temperature increase of the retina is insufficient to induce damage. $\odot 2011$ Society of Photo-Optical Instrumentation Engineers (SPIE). [DOI: 10.1117/1.3631788]
\end{abstract}

Keywords: lasers in medicine; laser applications; biomedical optics; ophthalmology; laser in situ keratomileusis; thermal effect. Paper 11185RR received Apr. 12, 2011; revised manuscript received Aug. 2, 2011; accepted for publication Aug. 8, 2011; published online Oct. 3, 2011.

\section{Introduction}

Multiple commercial femtosecond laser systems are approved by the U.S. Food and Drug Administration for refractive surgery. ${ }^{1-3}$ This procedure involves cutting of a thin flap in the cornea either with a fine blade (microkeratome) or a femtosecond laser (so called bladeless method) in order to expose the stromal bed for the excimer laser ablation in a laser in situ keratomileusis (LASIK) procedure, which is the most common refractive surgical method in the United States (US) today. ${ }^{4-8}$ Due to the advantage of the enhanced precision and minimized collateral tissue effects, femtosecond lasers have displaced the mechanical microkeratome as the dominant tool for LASIK flap creation in the US over the past decade. ${ }^{9-15}$ Diode pumped all-solid-state femtosecond lasers are now also commonly used to perform corneal transplants ${ }^{16-18}$ or being investigated to perform additional procedures, such as fs-lentotomy. ${ }^{19-21}$

The iFS advanced femtosecond laser (AMO Inc., Santa Ana, California) is the most popular laser machine on the US market. In contrast to initial systems, which operated at repetition rates of a few kilohertz, newer systems have introduced a progressive increase in repetition emission frequencies up to 15,30 , 60 , and $150 \mathrm{kHz} .^{22-24}$ The increase in laser repetition permits the creation of a standard LASIK flap in a shorter time, which dramatically decreases the duration of the LASIK procedure. However, the higher repetition rate is accompanied by an increase of the average power reaching the retina with a potential risk of thermal damage. Preliminary estimates suggest that 50 to $60 \%$ of laser energy passes beyond the cornea with a potential hazard to the retina and iris. ${ }^{25-27}$ A safety assessment can

Address all correspondence to: Tibor Juhasz, University of California-Irvine, Department of Ophthalmology, 118 Med Surge I, Irvine, California 92697; Tel: 949-824-1148; Fax: 949-824-4015; E-mail: tjuhasz@uci.edu. provide an analysis of exposure relative to established exposure limits. ANSI Z136.1-2007 series provides internationally accepted exposure limits. According to ANSI Z136.1-2007, the photodisprupiton threshold for iFS advanced femtosecond laser is about $1 \mathrm{~J} / \mathrm{cm}^{2}$. At flap procedure, the fluence at the cornea is at a range from 1 to $2 \mathrm{~J} / \mathrm{cm}^{2}$. For efficient flap cutting, the laser is tightly focused to the cornea, which results in a transmitted beam with a diameter of approximately $10 \mathrm{~mm}$ on the retina. The fluence on the retina is approximately 10 million times below the photodisruption threshold. ${ }^{28}$ Although photodisruptive damage in the retina does not occur, the femtosecond laser light reaching the retina is absorbed by the tissue and its energy is converted to heat.

Simulation of the temperature distribution may be an appropriate method to quantify the thermal effects of the femtosecond laser in the retina. Although the finite element method has frequently been used to calculate the intra-ocular temperature rise induced by laser illumination, a systematic study concerning the temperature increase induced by femtosecond lasers in the retina is still lacking. ${ }^{29-33}$ In this paper, we present a twodimensional computer simulation of the temperature field in a human cadaver retina exposed to the femtosecond laser based on the heat-transport equation solved by the COMSOL finite element software (Comsol Inc., Burlington, Massachusetts). The simulation data were compared with the temperature increase measured by an infrared thermal camera in a human cadaver retina in an ex vivo experiment using a $150-\mathrm{kHz}$ iFS advanced femtosecond laser (AMO Inc., Santa Ana, California) previously reported by our group. ${ }^{25}$ In addition, we also simulated the temperature increase using the $60-\mathrm{kHz}$ FS60 laser (AMO Inc., Santa Ana, California), the FEMTEC system (Technolas Perfect Vision Inc., Heidelberg, Germany), and the VisuMax system (Carl Zeiss Inc., Jena, Germany).

1083-3668/2011/16(10)/108001/8/\$25.00 @ 2011 SPIE 


\section{Materials and Methods}

\subsection{Finite Element Model}

\subsubsection{Basic assumptions}

A finite element model was developed to simulate the temperature increase in a human cadaver retina during the direct illumination by femtosecond laser pulses on the following assumptions:

1. Although the real human retina consists of ten cell layers; namely the inner limiting membrane, the nerve fiber layer, the ganglion cell layer, the inner plexiform layer, the inner nuclear layer, the outer plexiform layer, the outer nuclear layer, the outer limiting membrane, the rods and cones layer and, the retinal pigment epithelium (RPE); for simplification of the simulation, the retina was modeled as a four isotropic layer structure. ${ }^{34} \mathrm{~A}$ cross section of the retina was considered $11 \mathrm{~mm}$ in length and $1514 \mu \mathrm{m}$ in thickness.

2. An average refractive index of the tissue along the path of the laser beam was assumed to be 1.33 and any light scattering inside the eye was neglected. We assumed that the iris and the flap are aligned parallel during the LASIK procedure due to corneal applanation by the patient interface and estimated the distance from the corneal surface to the lens to be $3 \mathrm{~mm}$. We assumed that the thickness of the crystalline lens is $4 \mathrm{~mm}$. We assumed that the distance from the corneal surface to the surface of the retina is $22 \mathrm{~mm}$.

3. The high concentration of melanin pigments in retina is the main factor for the absorption of laser energy at IR-A region (wavelengths between 780 and $1400 \mathrm{~nm}$ ). ${ }^{35}$ The reflectivity of the human cadaver retina is set according to Watts' data from a pigmented rabbit iris since the iris also contains a high concentration of melanin pigments. ${ }^{36}$

4. Three boundary conditions are provided by the commercial software: insulation, heat flux, and temperature. The upper surface of the sample was chosen to the heat flux boundary condition and other surfaces of the sample were chosen to temperature boundary condition. The room temperature is set to $20^{\circ} \mathrm{C}$ for the boundary condition during simulation. The heat exchange surrounding the retina plays an important role as a boundary condition. The heat transfer coefficient was chosen as from water to air and its value was determined according to the Williams' experiment. ${ }^{37}$ The equation for the heat flux boundary condition is

$$
k \nabla T=h\left(T_{\mathrm{inf}}-T\right),
$$

where $k$ is the thermal conductivity $(\mathrm{W} / \mathrm{m} * \mathrm{k}), h$ is the heat transfer coefficient $\left(36.5\right.$ at $\left.20^{\circ} \mathrm{C}\right)$, and $T_{\text {inf }}$ is the external temperature.

5. We assumed that the iris is sufficiently large to allow transmission of all of the light through the lens. Schumacher et al. estimated the radius of the irradiated area at the retina as a function of the numerical aperture of the focusing lens. ${ }^{38}$ Ex vivo experiments were performed to validate the results of the model. To obtain the same beam diameter on the dissected retina in the air as obtained with the numerical aperture of the iFS advanced femtosecond laser during the actual surgery in the eye, we positioned the retina sections $17 \mathrm{~mm}$ from the focal point of the objective in the experiment. The size of the retina sample was $11 \mathrm{~mm} \times 11 \mathrm{~mm} .^{25}$

6. We assumed no heat flow due to blood flow in the choroid and sclera.

\subsubsection{Mathematical model}

The finite element model was created using the commercially available Comsol Multiphysics finite element software package (Comsol Inc., Burlington, Massachusetts). The retina was modeled as a four-layer structure. The first layer is the neuro-sensory retina, which is transparent to the laser beam; the second layer is the retina pigment epithelium (RPE), which is strongly absorbs the illumination; the third layer represents the choroid, which is also an absorber for the incident laser; and the fourth layer represents the sclera. Although the neural retina is not a constant $200 \mu \mathrm{m}$ thickness, for example at the foveal pit, the retina thickness is about $150 \mu \mathrm{m}$, the foveal rim is about $320 \mu \mathrm{m}$, the peripapillary is about $340 \mu \mathrm{m}$, and the equator is about $100 \mu \mathrm{m}$. For comparison with the other models at the retina heating study, the neural retina chooses the same thickness of about $200 \mu \mathrm{m}$; the RPE is a highly pigmented hexagonal monolayer with about $14-\mu \mathrm{m}$ thickness and is found between the photoreceptors and choroid; the choroid is a layer with about $300-\mu \mathrm{m}$ thickness and is found between the RPE and sclera; the thickness of sclera is $1000 \mu \mathrm{m} .{ }^{39}$ Heat transfer through the conduction and convection models was employed for the simulation. The time-dependent heat distribution in the model is governed by the heat diffusion equation due to the absorption of illumination laser pulses

$$
\rho C_{p} \frac{\partial T}{\partial t}+\nabla \times(-k \nabla T)=Q,
$$

where $\rho$ is the density $\left(\mathrm{kg} / \mathrm{m}^{3}\right), C_{p}$ is the heat capacity at constant pressure $\left(\mathrm{J} / \mathrm{kg}^{*} \mathrm{k}\right), k$ is the thermal conductivity $(\mathrm{W} / \mathrm{m} * \mathrm{k})$, and $Q$ is the amount of laser energy absorbed by the tissue. The RPE and choroid layers absorb energy from the laser and convert it to heat, which is then transferred to the other surrounding layers. In the simulation, the illumination laser beam parameters were assumed to be the same as those applied in the ex vivo experiments previously reported. ${ }^{25}$ Some of the thermal properties of the neuro-sensory retina, RPE, and choroid layers were chosen to be identical to those of water. Specifically, the thermal conductivity, density, thickness, and specific heat capacity of such four layers in the model are shown in Table 1. Laser energy deposition was modeled as a heat source in the RPE and choroid layers. The heat source terms were calculated using the laser parameters and the absorption coefficients of the RPE and choroid, which are 100 and $25 \mathrm{~cm}^{-1}$, respectively. ${ }^{29,30,40-45}$ Equation (2) was solved by COMSOL finite element software (Comsol Inc., Burlington, Massachusetts) with the finite element mesh and boundary conditions described above. The heat source term varies with laser pulse energy and we simulated the temperature increase at different laser pulse energy levels ranging from 0.3 to $1.6 \mu \mathrm{J}$.

Using the model described above, we also calculated the temperature increase in the retina sample using the $60-\mathrm{kHz}$ FS60 
Table 1 Material constants.

\begin{tabular}{lcccc}
\hline & $\begin{array}{c}\text { Density } \\
(\rho)\end{array}$ & $\begin{array}{c}\text { Heat capacity } \\
\left(\mathrm{C}_{\mathrm{p}}\right)\end{array}$ & $\begin{array}{c}\text { Thermal } \\
\text { conductivity }(\mathrm{k})\end{array}$ & $\begin{array}{c}\text { Thickness } \\
(\mu \mathrm{m})\end{array}$ \\
\hline Retina & 1000 & 4178 & 0.58 & 200 \\
RPE & 1000 & 4190 & 0.628 & 14 \\
Choroid & 1000 & 4178 & 0.58 & 300 \\
Sclera & 1050 & 3180 & 1.0042 & 1000 \\
\hline
\end{tabular}

laser, the 40-kHz FEMTEC femtosecond laser, and the $200 \mathrm{kHz}$ VisuMax femtosecond laser assuming a similar focusing geometry to that of the $150-\mathrm{kHz}$ iFS advanced femtosecond laser. The typical procedure time of flap creation for different laser systems is the following: $15 \mathrm{~s}$ for $150-\mathrm{kHz}$ iFS advanced femtosecond laser, $24 \mathrm{~s}$ for $60-\mathrm{kHz}$ FS60 laser, 12 to $16 \mathrm{~s}$ for 40-kHz FEMTEC femtosecond laser, and $40 \mathrm{~s}$ for $200-\mathrm{kHz}$ VisuMax femtosecond laser. $^{46,47}$ We compared the simulation results for the $150-\mathrm{kHz}$ iFS advanced femtosecond laser to the temperature measured by infrared thermal camera in ex vivo human cadaver retinas previously reported. ${ }^{25}$ Based on the thermal sensitivity of the camera $\left(0.08^{\circ} \mathrm{C}\right)$, we have chosen a time duration of $52 \mathrm{~s}$ for illumination time. Therefore, we model the temperature increase for both the 52-s illumination time and the typical clinical procedure time period of each laser system.

\subsection{Ex Vivo Experiment}

The temperature increase induced by the $150-\mathrm{kHz}$ iFS advanced femtosecond laser in a human cadaver retina was measured in situ using an infrared thermal imaging camera; details have been reported in our previous publication. ${ }^{25}$

\section{Results}

Simulation results show the temperature distribution in a cross section of retina for every second under the laser illumination for the 52-s long flap procedure, which is longer than the characteristic procedure time of the lasers discussed in this paper. Using parameters for the $150-\mathrm{kHz}$ iFS advanced femtosecond laser according to our model, the temperature in the retina increased up to $0.44,0.8$, and $1.44^{\circ} \mathrm{C}$ for laser pulse energies of $0.4,0.8$, and $1.6 \mu \mathrm{J}$, respectively. Figure 1 shows the simulation of the temperature distribution in the cross section of a retina at $0.4-\mu \mathrm{J}$ laser pulse energy and $150-\mathrm{kHz}$ repetition rate. The temperature of the retina sample before the laser illumination was assumed to be $20^{\circ} \mathrm{C}$. The maximum temperature increase was $0.44^{\circ} \mathrm{C}$. This result is in good agreement with the data measured by the infrared thermal camera in the ex vivo experiment where the mean temperature increase was $0.35 \pm 0.04^{\circ} \mathrm{C}$. The highest temperature of the retina as a function of time calculated from the model is shown in the inset of Fig. 1. Figure 2 shows the simulation of the temperature increase in the cross section of the retina at $0.8-\mu \mathrm{J}$ laser pulse energy and $150-\mathrm{kHz}$ repetition rate. The maximum temperature rise was $0.8^{\circ} \mathrm{C}$, which is close to the measured mean temperature rise $0.69 \pm 0.06^{\circ} \mathrm{C}$. The highest temperature of the retina as a function of time at $0.8-\mu \mathrm{J}$ laser pulse energy and $150-\mathrm{kHz}$ repetition rate is shown in the inset of Fig. 2. Figure 2 also shows that at a typical clinical setting ( 0.8 - to $1-\mu \mathrm{J}$ laser pulse energy and 15 -s procedure time), the temperature increase is $0.2^{\circ} \mathrm{C}$. Figure 3 shows the simulation of the temperature increase in the retina at $1.6-\mu \mathrm{J}$ laser pulse energy and $150-\mathrm{kHz}$ repetition rate. The highest temperature of the retina as a function of time at 1.6- $\mu \mathrm{J}$ laser pulse energy and

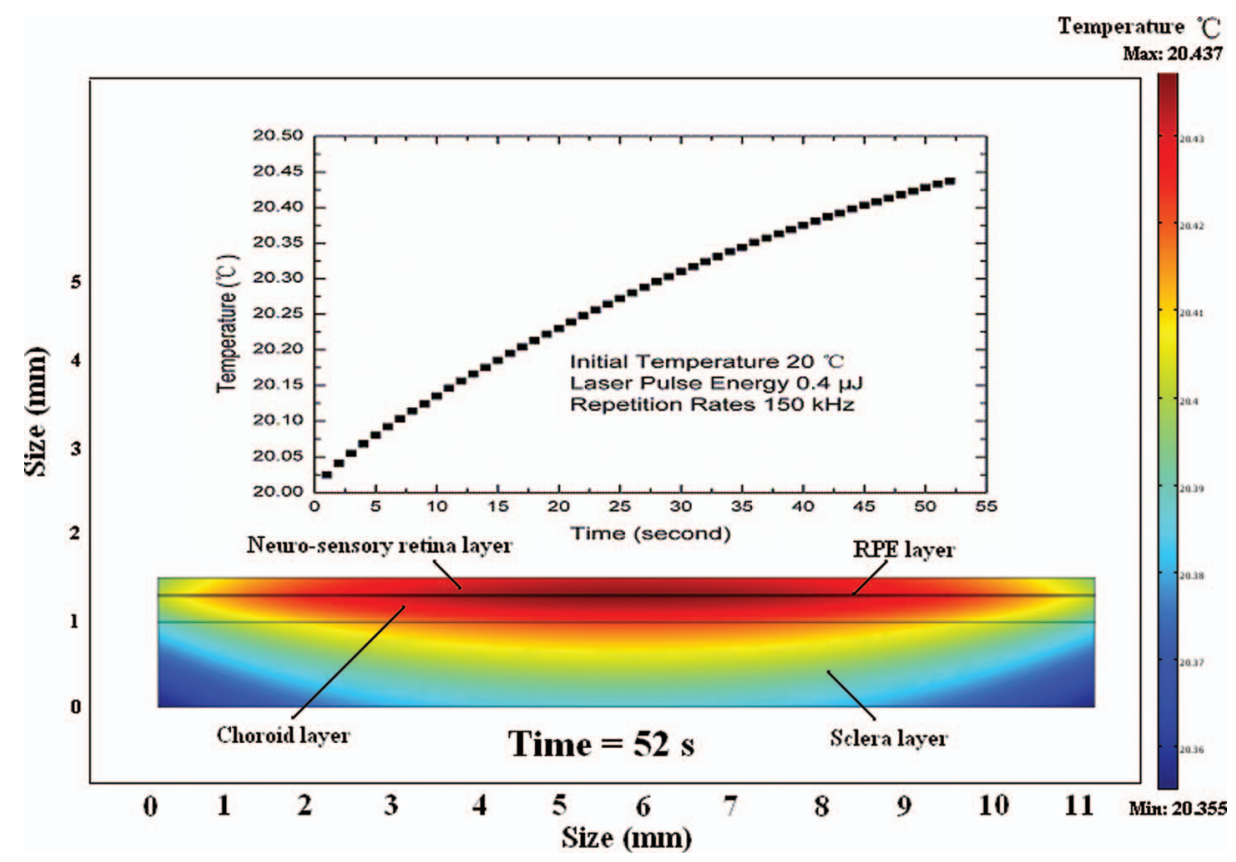

Fig. 1 Simulation of the temperature distribution in the retina sample at $0.4-\mu$ ) laser pulse energy and $150-\mathrm{kHz}$ repetition rate for 52 -s flap procedure. Inset: maximum temperature of the retina as a function of time calculated from the model. 


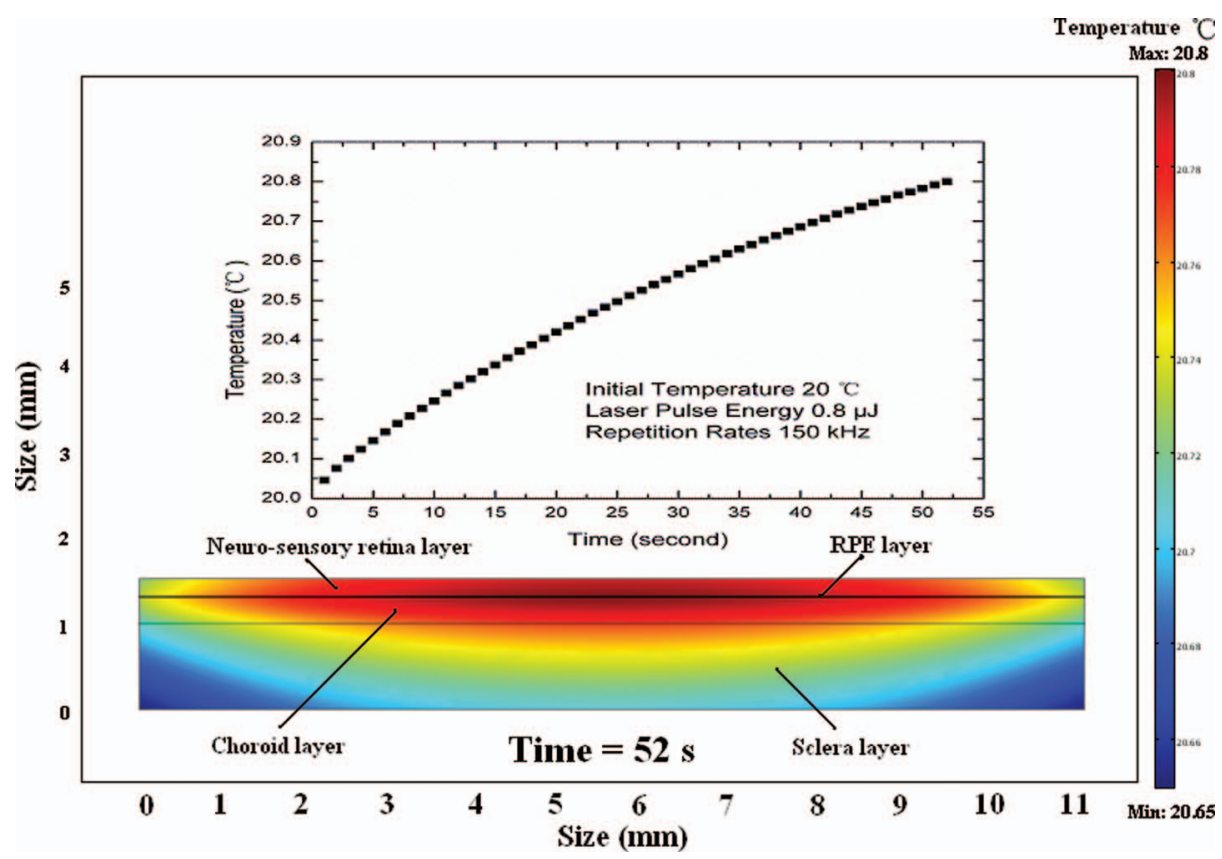

Fig. 2 Simulation of the temperature distribution in the retina sample at $0.8-\mu$ J laser pulse energy and $150-\mathrm{kHz}$ repetition rate for $52-\mathrm{s}$ flap procedure. Inset: maximum temperature of the retina as a function of time calculated from the model.

$150-\mathrm{kHz}$ repetition rate is shown in the inset of Fig. 3. Figure 3 also shows that at a typical clinical time setting (15-s procedure time), the temperature increase is $0.61^{\circ} \mathrm{C}$. The maximum temperature rise was $1.44^{\circ} \mathrm{C}$, which is close to the measured mean temperature rise $1.15 \pm 0.08^{\circ} \mathrm{C}$. The other advantage of the simulation is the ability to describe the temperature distribution inside the retina sample, which cannot be directly measured by an infrared thermal camera. Figure 4 represents the simulated temperature profile across the retina starting at the surface of the neuro-sensory retina considered as the first layer $(0 \mathrm{~mm}$ on the $x$ axis) and ending at the sclera considered as the fourth layer ( $1.514 \mathrm{~mm}$ on the $x$ axis). The temperature increase was modeled after a 52-s illumination time at laser pulse energy $1.6 \mu \mathrm{J}$. Based on our model, the maximum temperature increase is at the choroid layer (between 0.214 and $0.514 \mathrm{~mm}$ ) and the difference from the surface temperature is negligible $\left(0.022^{\circ} \mathrm{C}\right)$.

Even with the same boundary condition, the simulation shows that the temperature increase is nonlinear, i.e., it does not precisely double when the illumination laser energy increases from 0.4 to $0.8 \mu \mathrm{J}\left(0.44\right.$ and $\left.0.8^{\circ} \mathrm{C}\right)$ and from 0.8 to $1.6 \mu \mathrm{J}$

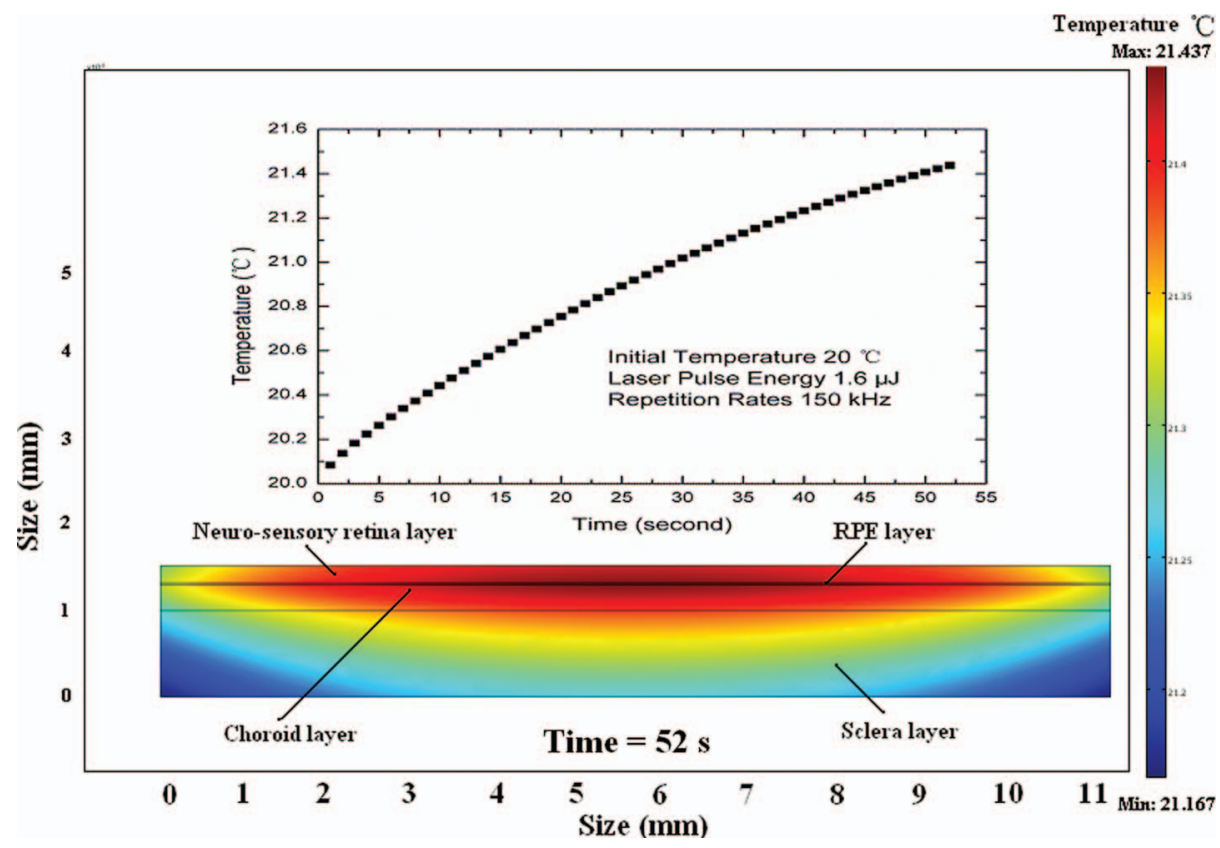

Fig. 3 Simulation of the temperature distribution in the retina sample at 1.6- $\mu$ J laser pulse energy and 150-kHz repetition rate for 52 -s flap procedure. Inset: maximum temperature of the retina as a function of time calculated from the model. 


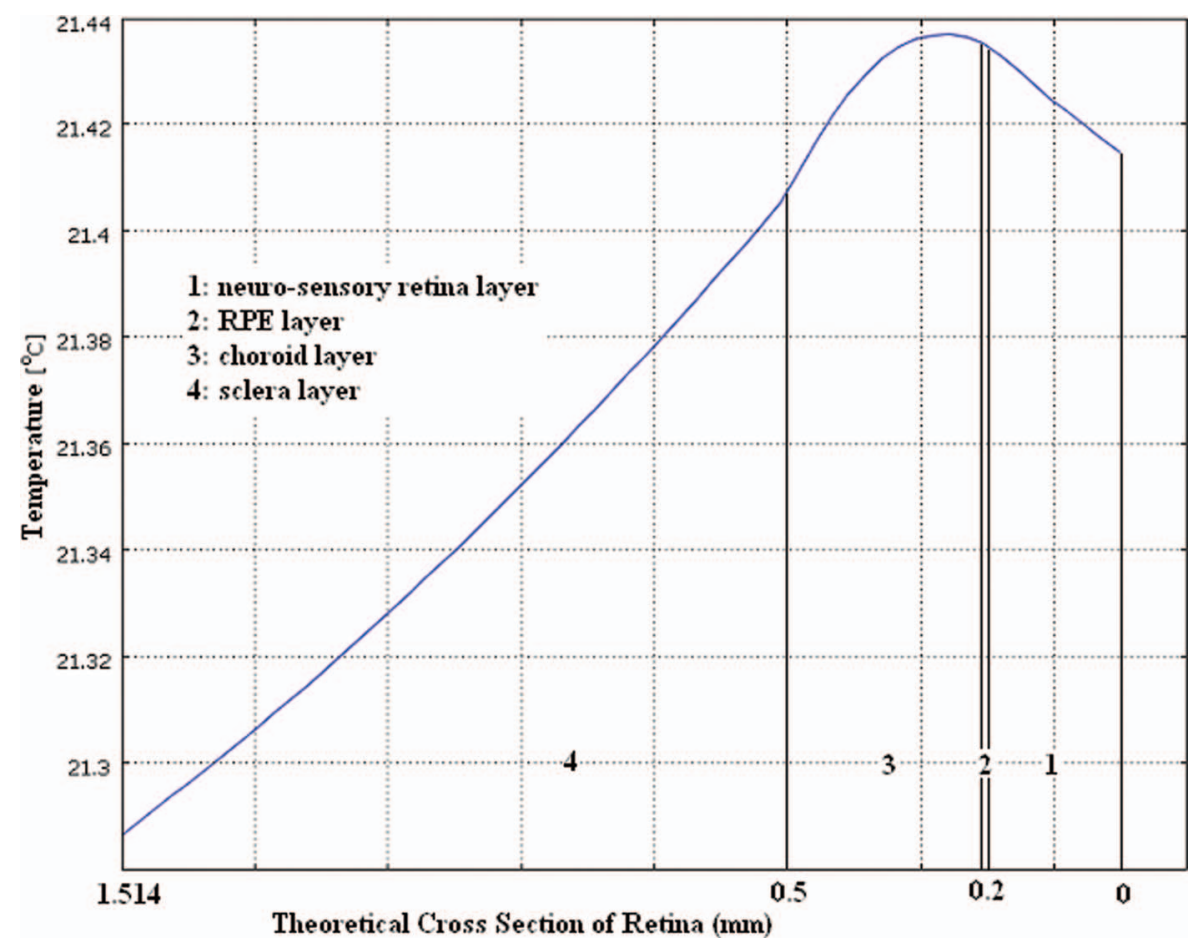

Fig. 4 Simulation of the temperature distribution inside of the retina model using 1.6- $\mu$ J laser pulse energy and 150-kHz repetition rate for 52-s flap procedure.

$\left(0.8\right.$ and $\left.1.44{ }^{\circ} \mathrm{C}\right)$. The accuracy and the predictability of the simulation are evaluated through comparison of the results with the actual measured data. For this comparison, the initial temperature of the retina in the model was chosen to be identical to the initial temperature of the retina in the ex vivo experiments. Figure 5 shows one of these comparisons as a function of time using 1.6- $\mu \mathrm{J}$ laser pulse energy and $150-\mathrm{kHz}$ repetition rate. The temperature increased up to $1.44^{\circ} \mathrm{C}$ in the human cadaver retina from simulation showing little variation in temperature profile compared with results for the same laser energy illumination in the ex vivo experiment.

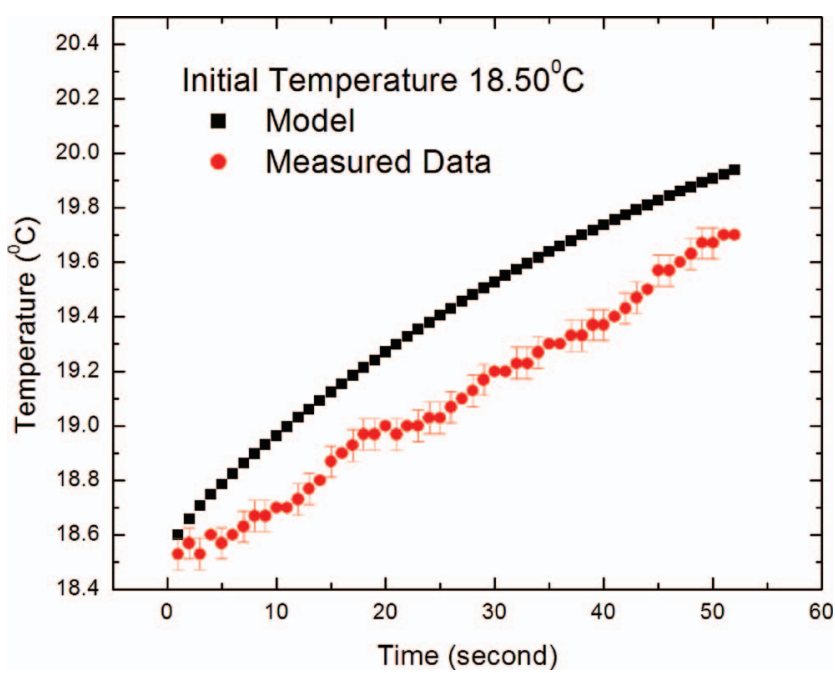

Fig. 5 Temperature rise comparisons of modeled results with actual measured data as a function of time for 1.6- $\mu \mathrm{J}$ laser pulse energy and $150-\mathrm{kHz}$ repetition rate of $52-\mathrm{s}$ flap procedure.
Although, the $150-\mathrm{kHz}$ iFS advanced femtosecond laser has the highest repetition rates among the products of AMO Inc., their $60-\mathrm{kHz}$ FS60 laser is the most popular machine worldwide..$^{3,24,48-50}$ Due to this reason, we simulated the temperature increase for the 60-kHz FS60 laser using pulse energy $1.6 \mu \mathrm{J}$. In addition, we also modeled the temperature increase for two other systems: we used 1.4- $\mu \mathrm{J}$ laser pulse energy for the $40-\mathrm{kHz}$ FEMTEC system and $0.3-\mu \mathrm{J}$ laser pulse energy for the $200-\mathrm{kHz}$ VisuMax system. The laser pulse energies chosen by us are regularly used in clinical practice. ${ }^{51-53}$ For the simulation, we have chosen the illumination time used in the ex vivo experiments discussed in Ref. 25. The results of these three simulations are presented in Fig. 6. The arrows of Fig. 6 show the temperature increase at the typical procedure time points for each laser system: $0.34^{\circ} \mathrm{C}$ for $60-\mathrm{kHz}$ FS60 laser (at $24 \mathrm{~s}$ ), $0.15^{\circ} \mathrm{C}$ for $40-\mathrm{kHz}$ FEMTEC system (at $16 \mathrm{~s}$ ), and $0.46^{\circ} \mathrm{C}$ for 200-kHz VisuMax system(at $40 \mathrm{~s}$ ).

\section{Discussion}

Since in vivo investigations of retinal heating by laser radiation is rather difficult, numerical simulation may be a viable solution to estimate the heating effect during femtosecond laser eye surgery. Refined models have the potential to be particularly effective because the heat transport within the ocular tissue occurs mostly by conduction, which can be precisely predicted by a heat conduction equation together with proper boundary conditions. ${ }^{35}$ It is suitable to represent the temperature distribution in the retina sample by using a two-dimensional model because of the axial symmetry of both the ocular tissue and the absorbed laser power distribution. ${ }^{31}$ The theoretical model presented here attempts to estimate the temperature increase in a 


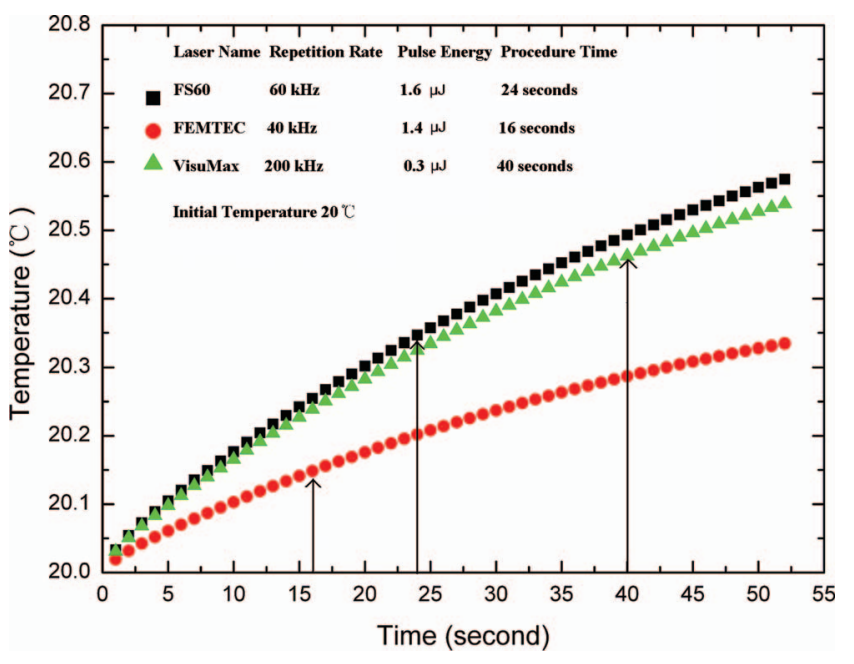

Fig. 6 Simulation of the temperature distribution in the retina sample for three different laser systems: $60-\mathrm{kHz}$ FS60 laser, 40-kHz FEMTEC system, and 200-kHz VisuMax system. The arrows show the temperature increase at the time of the typical clinical setting for each laser system.

human cadaver retina during the corneal flap cutting procedure using several commercial femtosecond laser systems. The model was validated by comparing predictions to experimental results obtained with the $150-\mathrm{kHz}$ iFS femtosecond laser. ${ }^{25}$ Data from the ex vivo experiments indicate that all retina samples showed similar behavior when the same laser parameters were applied. ${ }^{25}$ Tissue properties, such as variability in pigmentation within the selected group, did not considerably influence the results and was ignored at simulation. The reason for lower measurements compared to the model may be because the cadaver retina tissue absorption coefficient is lower than the literatures suggest. To simplify the calculation, scanning was neglected since the tightly focused spot at the cornea will project a spot with almost a $10-\mathrm{mm}$ diameter at the retina. More specifically, it was assumed that the entire retina sample had been uniformly illuminated with the laser beam for $52 \mathrm{~s}$. Both the temperature on the surface and the temperature distribution across the retina were calculated. At the typical clinical energy and time settings of the flap procedure ( 0.8 - to $1-\mu \mathrm{J}$ laser pulse energy and a 15 -s procedure time), the temperature increase does not exceed $0.2^{\circ} \mathrm{C}$ in the retina. The simulated temperatures are in good agreement with the results obtained from the ex vivo experiments. Additionally, the maximum temperature increase inside of the retina is only slightly different from its surface temperature. In an unlikely event that photo disruption does not occur (e.g., due to the laser beam distortions), the incident average pulse power may reach the 1.6- $\mu \mathrm{J}$ laser pulse energy in the retina. Our model shows that even in this worst case scenario, the temperature increase in the retina will not exceed $0.61{ }^{\circ} \mathrm{C}$ at the end of a 15 -s flap procedure time indicating that femtosecond laser corneal flap cutting does not present a hazard to the retina. In fact, the actual temperature increase in an in vivo retina would be expected to be even smaller, due to the presence of heat sinks (vitreous, aqueous humor) and the cooling effect of local blood flow. ${ }^{54}$

Our conclusions are in good agreement with the findings of Sander et al. ${ }^{55}$ where a histopathological study of the retina of porcine cadaver eyes was used to establish the safety of femtosecond laser flap cutting procedures with the $60-\mathrm{kHz}$ IntraLase $^{\mathrm{TM}}$ FS laser (AMO Inc., Santa Ana, California). Our results can also be compared to the results published by Sailer et al., who investigated the thermal effects of continuous wave laser radiation at a wavelength of $830 \mathrm{~nm}$ on the retina of live rabbits. ${ }^{56}$ At an average power of $40 \mathrm{~mW}$ and an illumination time satisfactorily long to achieve equilibrium temperature in the retina, they found a maximum temperature rise of about $4.5^{\circ} \mathrm{C}$ with no acute damage observed in the subsequent histological examination of the immediately enucleated rabbit eye. In contrast, we used a different wavelength $(1053 \mathrm{~nm})$ and a considerably shorter illumination time; therefore, equilibrium temperature is not reached in our simulation and experiment. In addition, using the simulation model we have also proven that other commercial femtosecond systems marketed for flap creation $(60-\mathrm{kHz}$ FS60 laser, 40-kHz FEMTEC femtosecond laser, and $200-\mathrm{kHz}$ VisuMax femtosecond laser) present no thermal hazard to the retina if the average power on target and the total laser energy used for the procedures are similar in magnitude than those used in our current study. Other possible types of laser injury to the retina, such as mutagenesis or altered cellular function, are not investigated in our studies. However, the biological safety of the 1053-nm wavelength of the iFS laser has been well established. ${ }^{57-60}$ Additionally, the relatively short illumination time also eliminates the possibility of mutagenesis or altered retina cellular function.

The focusing geometry alone may not determine a laser's distribution on the retina because of nonlinear propagation effects in the eye. ${ }^{61,62}$ Cain et al. ${ }^{61}$ and Schulmeister et al. ${ }^{62}$ studied the visible lesion threshold dependence on retinal spot size for femtosecond laser pulses. In their cases, the retinal image sizes are at a $\mu \mathrm{m}$ range and in our cases the retinal image sizes are at a $\mathrm{mm}$ range so that even the nonlinear propagation effects in the eye decrease the retinal image size; the fluence on the retina is still very far below the photodisruption threshold. Recent work by Denton et al. has demonstrated photo-oxidative stress generated by high repetition rate femtosecond pulses. ${ }^{63}$ They used a very high repetition rate laser at $80 \mathrm{MHz}$ and a very short laser pulse duration at 90 femtosecond at a wavelength $810 \mathrm{~nm}$. In their experiment they focused the laser beam to the sample. During flap procedures, the spot size of the laser on the retina is in the mm range. The repetition rate of the iFS laser is $150 \mathrm{kHz}$, that is very low compared to $80 \mathrm{MHz}$. The pulse duration of the iFS laser is about 500 femtosecond and much longer than 90 femtosecond. The wavelength of $1053 \mathrm{~nm}$ for the iFS laser is longer than $810 \mathrm{~nm}$ in their case and the eye tissue should be more insensitive at $1053 \mathrm{~nm}$. Our laser parameters are much different from those in the Denton et al. study, so it is possible that our laser does not induce photo-oxidation.

In summary, the two-dimensional computer simulation seems to be a reasonable method to predict the thermal effect of the femtosecond lasers in the retina during LASIK surgery. Using this model, we have shown that commercial femtosecond laser systems marketed for flap creation present no thermal hazard to the retina.

\section{Acknowledgments}

This work was supported by the National Institutes of Health (NIH Grant No. R01 EY 018665). 


\section{References}

1. T. Juhasz, F. H. Loesel, R. M. Kurtz, C. Horvath, J. F. Bille, and G. Mourou, "Corneal refractive surgery with femtosecond lasers," IEEE J. Sel. Top. Quantum Electron. 5, 902-910 (1999)

2. T. Juhasz, G. Djotyan, F. H. Loesel, R. M. Kurtz, C. Horvath, J. F. Bille, and G. Mourou, "Applications of femtosecond lasers in corneal surgery," Laser Phys. 10(2), 495-500 (2000).

3. H. Lubatschowski, "Overview of commercially available femtosecond lasers in refractive surgery," J. Refract. Surg. 24(1), 102-107 (2008).

4. P. S. Binder, M. Sarayba, T. Ignacio, T. Juhasz, and R. M. Kurtz, "Characterization of submicrojoule femtosecond laser corneal tissue dissection," J. Cataract Refractive Surg. 34(1), 146-152 (2008).

5. I. G. Pallikaris, M. E. Papatzanaki, D. S. Siganos, and M. K. Tsilimbaris, "A corneal flap technique for laser in situ keratomileusis; human studies," Graefes Arch. Ophthalmol. 109, 1699-1702 (1991).

6. K. Liu and D. S. C. Lam, "Direct measurement of microkeratome gap width by electron microscope," J. Cataract Refractive Surg. 27(6), 924927 (2001).

7. J. Javaloy, M. T. Vidal, J. M. Ruiz-Moreno, and J. L. Alió, "Confocal microscopy of disposable and nondisposable heads for the Moria M2 microkeratome," J. Refract. Surg. 22(1), 28-33 (2006).

8. S. G. Slade, "The use of the femtosecond laser in the customization of corneal flaps in laser in situ keratomileusis," Current Opinion in Ophthalmology 18(4), 314-317 (2007).

9. H. Sun, M. Han, M. H. Niemz, and J. F. Bille, "Femtosecond laser ablation threshold: dependence on tissue depth and laser pulse width," Lasers Surg. Med. 39(8), 654-658 (2007).

10. M. Han, G. Giese, L. Zickler, H. Sun, and J. F. Bille, "Mini-invasive corneal surgery and imaging with femtosecond lasers," Opt. Express 12, 4275-4281 (2004)

11. J. F. Bille, C. F. H Harner, and F. Loesel, New Frontiers in Vision and Aberration-Free Refractive Surgery, Springer-Verlag, Berlin (2002).

12. L. T. Nordan, S. G. Slade, R. N. Baker, C. Suarez, T. Juhasz, and R. M Kurtz, "Femtosecond laser flap creation for laser in situ keratomileusis: six-month follow-up of initial US clinical series," J. Refract. Surg. 19(1), 8-14 (2003).

13. W. Yanyan, H. Meng, S. Hui, J. Bille, and R. Qiushi, "Second harmonic generation microscopy imaging of cornea after femtosecond laser intrastromal ablation,” Acta Laser Biology Sinica 14(5), 321-326 (2005).

14. I. Ratkay-Traub, I. E. Ferincz, T. Juhasz, R. M. Kurtz, and R. R. Krueger, "First clinical results with the femtosecond neodynium-glass laser in refractive surgery," J. Refract. Surg. 19(2), 94-103 (2003).

15. M. H. Niemz, Laser-Tissue Interactions - Fundamentals and Applications, 3rd ed., Springer-Verlag, Berlin (2003).

16. M. A. Terry, P. J. Ousley, and B. Will, "A practical femtosecond laser procedure for DLEK endothelial transplantation - cadaver eye histology and topography," Cornea 24(4), 453-459 (2005).

17. J. B. Jonas, "Corneal endothelial transplantation using femtosecond laser technology," Eye 18(6), 657-658 (2004).

18. F. W. Price and M. O. Price, "Femtosecond laser shaped penetrating keratoplasty: one-year results utilizing a top-hat configuration," Am. J. Ophthalmol. 145(2), 210-214 (2008).

19. H. Lubatschowski, S. Schumacher, A. Wegener, M. Fromm, U. Oberheide, H. Hoffmann, and G. Gerten. "Fs-Lentotomy: presbyopia reversal by generating gliding planes inside the crystalline lens," Klin. Monatsbl. Augenheilkd. 226(12), 984-990 (2009).

20. F. H. Loesel, J. P. Fischer, M. H. Gotz, C. Horvath, T. Juhase, F. Nocak, N. Suhm, and J. F. Bille, "Non-thermal ablation of neural tissue with femtosecond laser pulses," Appl Phys B 66, 121-128 (1998).

21. F. H. Loesel, A.-C. Tien, S. Backus, H. C. Kapteyn, M. M. Murnane, R. M. Kurtz, S. I. Sayegh, and T. Juhasz, "Effect of reduction of laser pulse width from $100 \mathrm{ps}$ to $20 \mathrm{fs}$ on the plasma-mediated ablation of hard and soft tissue." Proc. SPIE 3565, 116-123 (1999).

22. M. A. Sarayba, T. S. Ignacio, P. S. Binder, and D. B. Tran, "Comparative study of stromal bed quality by using mechanical, intralase femtosecond laser 15- and 30-kHz microkeratomes," Cornea 26(4), 446-451 (2007).

23. M. Y. Hu, J. P. McCulley, H. D. Cavanagh, R. W. Bowman, S. M. Verity, V. V. Mootha, and W. M. Petroll. "Comparison of the corneal response to laser in situ keratomileusis with flap creation using the FS15 and FS30 femtosecond lasers: clinical and confocal microscopy findings," J. Cataract Refractive Surg. 33(4), 673-681 (2007).
24. W. M. Petroll, R. W. Bowman, H. D. Cavanagh, S. M. Verity, W. Mootha, and J. R. McCulley, "Assessment of keratocyte activation following LASIK with flap creation using the IntraLase FS60 laser," J. Refract. Surg. 24(8), 847-849 (2008)

25. H. Sun, E. Mikula, R. M. Kurtz, and T. Juhasz, "Temperature increase in human cadaver retina during direct illumination by femtosecond laser pulses," J. Refract. Surg. 26(4), 272-277 (2010).

26. R. L. Harzic, R. Bueckle, C. Wuellner, C. Donitzky, and K. Koenig, "Laser safety aspects for refractive eye surgery with femtosecond laser pulses," Med. Laser Appl. 20, 233-238 (2005).

27. H. Sun, R. M. Kurtz, E. R. Mikula, and T. Juhasz, "Temperature increase in porcine cadaver iris during direct illumination by femtosecond laser pulses," J. Cataract Refractive Surg. 37(2), 386-391 (2011).

28. B. A. Rockwell, R. J. Thomas, and A. Vogel, "Ultrashort laser pulse retinal damage mechanisms and their impact on thresholds," Med. Laser Appl. 25, 84-92 (2010).

29. A. S. Gabriela and L. H. Jean-Pierre, "Simulating and optimizing of argon laser iridectomy. Influence of irradiation duration on the corneal and lens thermal injury," Proc. SPIE 3564, 101-113 (1999).

30. B. Nemati, A. Dunn, A. J. Welch, and H. G. Rylander, "Optical model for light distribution during transscleral cyslophotoagulation," Appl. Opt. 37(4), 764-771 (1998).

31. J. J. W. Lagendijk, "A mathematical model to calculate temperature distributions in human and rabbit eyes during hyperthermic treatment," Phys. Med. Biol. 27(11), 1301-1311 (1982).

32. J. A. Scott, "A finite element model of heat transport in the human eye," Phys. Med. Biol. 33(2), 227-241 (1988).

33. J. A. Scott, "The computation of temperature rises in the human eye induced by infrared radiation," Phys. Med. Biol. 33(2), 243-257 (1988).

34. C. E. Willoughby, D. Ponzin, S. Ferrari, A. Lobo, K. Landau, and Y Omidi, "Anatomy and physiology of the human eye: effects of mucopolysaccharidoses disease on structure and function-a review," Clin. Exp. Ophthalmol. 38(Suppl. 1), 2-11 (2010).

35. T. Okuno, "Thermal effect of infrared radiation on the eye - a study based on a model," Ann. Occup. Hyg. 25(1), 1-12 (1991).

36. G. K. Watts, "Retinal hazards during laser irradiation of iris," $\mathrm{Br}$. $J$. Ophthalmol. 55(1), 60-67 (1971).

37. G. P. Williams, "Heat transfer coefficients for natural water surfaces," in Proc. Int. Assoc. Sci. Hydrol., IUGG Publ. 62, 203-212 (1963).

38. S. Schumacher, M. Sander, A. Stolte, C. Doepke, W. Baumgaertner, and H. Lubatschowski, "Investigation of possible fs-LASIK induced retinal damage," Proc. SPIE 6138, 61381I (2006)

39. C. W Oyster, The Human Eye: Structure and Function, Sunderland Massachusetts, Sinauer Associates, Sunderland, MA (1999).

40. E. H. Ooi, W. T. Ang, and E. Y. K. Ng, "Bioheat transfer in the human eye: a boundary element approach," Eng. Anal. Boundary Elem. 31, 494-500 (2007).

41. M. Paruch, "Numerical simulation of bioheat transfer process in the human eye using finite element method," Scientific Research of the Institute of Mathematics and Computer Science, Czustochowa, Poland, Vol. 1, pp. 199-207 (2007).

42. W. J. Geeraets, R. C. Williams, G. Chan, W. T. Ham, D. Guerry, and F. H. Schmidt, "The relative absorption of thermal energy in retina and choroid," Invest. Ophthalmol. 1(3), 340-347 (1962).

43. M. A. Mainster, T. J. White, J. H. Tips, and P. W. Wilson, "Retina temperature increases produced by intense light sources," J. Opt. Soc. Am. 60(2), 264-271 (1970).

44. E. H. Amara, "Numerical investigations on thermal effects of laser ocular media interaction," Int. J. Heat Mass Transfer 38, 2479-2488 (1995).

45. A. S. Gabriela and L. H. Jean-Pierre, "Modelling and simulating of argon laser iridectomy based on 3-D finite element method. Influence of laser parameters and pathological eye situation on the temperature history," Proc. SPIE 3192, 219-232 (1997).

46. M. Nubile, P. Carpineto, M. Lanzini, R. Calienno, L. Agnifili, M. Ciancaglini, and L. Mastropasqua, "Femtosecond laser arcuate keratotomy for the correction of high astigmatism after keratoplasty," Ophthalmology 116(6), 1083-1092 (2009).

47. D. Z. Reinstein, T. J. Archer, M. Gobbe, and N. Johnson, “Accuracy and reproducibility of artemis central flap thickness and visual outcomes of LASIK with the carl zeiss meditec visumax femtosecond laser and 
mel 80 excimer laser platforms," J. Refractive Surg. 26(2), 107-119 (2010).

48. T. Kohnen, O. K. Klaproth, V. Derhartunian, and D. Kook, "Results of 308 consecutive femtosecond laser cuts for LASIK," Ophthalmologe 107(5), 439-445 (2010).

49. V. Nuzzo, F. Aptel, M. Savoldelli, K. Plamann, D. Peyrot, F. Deloison, D. Donate, and J. M. Legeais, "Hostologic and ultrastructural characterization of corneal femtosecond laser trephination," Cornea 28(8), 908-913 (2009).

50. O. Muftuoglu, P. Prasher, C. Chu, W. Mootha, S. M. Verity, H. D. Cavanagh, R. W. Bowman, and J. P. McCulley, "Laser in situ keratomileusis for residual refractive errors after apodized diffractive multifocal intraocular lens implantation," J. Cataract Refractive Surg. 35(6), 1063-1071 (2009).

51. J. S. Mehta, R. Shilbayeh, Y. M. Por, H. Cajucom-Uy, R. W. Beuerman, and D. T. Tan, "Femtosecond laser creation of donor cornea buttons for Descemet-stripping endothelial keratoplasty," J. Cataract Refractive Surg. 34(11), 1970-1975 (2008).

52. J. Heichel, T. Hammer, R. Sietmann, G. I. W. Duncker, and F. Wilhelm, "Scanning electron microscopic characteristics of lamellar keratotomies using the Femtec femtosecond laser and the Zyoptix XP microkeratome. A comparison of quality," Ophthalmologe 107(4), 333-340 (2010).

53. W. Sekundo, K. Kunert, C. Russmann, A. Gille, W. Bissmann, G. Stobrawa, M. Sticker, M. Bischoff, and M. Blum, "First efficacy and safety study of femtosecond lenticule extraction for the correction of myopia-six month results," J. Cataract Refractive Surg. 34(9), 15131520 (2008).

54. E. A. Boettner and J. R. Wolter, "Transmission of the ocular media," Invest. Ophthalmol. 1, 776-783 (1962).
55. M. Sander, M. Mueller, and M. R. Tetz, "Possible retina damage potential of the femtosecond laser in situ keratomileusis (fs-LASIK) refractive surgery," Med Laser Appl. 23(1), 39-45 (2008).

56. H. Sailer, K. Shinoda, G. Blatsios, K. Kohler, L. Bondzio, E. Zrenner, and F. Gekeler, "Investigation of thermal effects of infrared lasers on the rabbit retina: a study in the course of development of an active subretinal prosthesis," Graefe's Arch. Clin. Exp. Ophthalmol. 245, 1169-1178 (2007).

57. M. Q. Salomao and S. E. Wilson, "Femtosecond laser in laser in situ keratomileusis," J. Cataract Refractive Surg. 36(6), 1024-1032 (2010).

58. M. Farid and R. F. Steinert, "Femtosecond laser-assisted corneal surgery," Curr. Opin. Ophthalmology 21(4), 288-292 (2010).

59. P. S. Binder, "Flap dimensions created with the intralaser FS laser," J. Cataract Refractive Surg. 30(1), 26-32 (2004).

60. D. B. Tran, M. A. Sarayba, Z. Bor, C. Garufis, Y. J. Duh, C. R. Soltes, T. Juhasz, and R. M. Kurtz, "Randomized prospective clinical study comparing induced aberrations with intralse and hansatome flap creation in fellow eyes-potential impact on wavefront-guided alser in situ keratomileusis," J. Cataract Refractive Surg. 31(1), 97-105 (2005).

61. C. P. Cain, C. A. Toth, G. D. Noojin, D. J. Stolarski, R. J. Thomas, S. Cora, and B. A. Rockwell, "Visible lesion threshold dependence on retinal spot size for femtosecond laser pulses," J. Laser Appl. 13(3), 125-131 (2001).

62. K. Schulmeister, J. Husinsky, B. Seiser, F. Edthofer, B. Fekete, L. Farmer, and D. J. Lund, "Ex vivo and computer model study on retinal thermal laser-induced damage in the visible wavelength range," J. Biomed. Opt. 13(5), 054038 (2008).

63. M. L. Denton, K. J. Schuster, and B. A. Rockwell, "Accurate measure of laser irradiance threshold for near-infrared photo-oxidation with a modified confocal microscope," J. Microsc. 221, 164-171 (2006). 